\title{
Storm-runoff processes in a mainly waterlogged low mountain range catchment in the national park Hunsrück-Hochwald, SW-Germany: Assessing the impact of wetland restoration using multiple linear regression analysis and ANCOVA.
}

\author{
Julian Zemke Z $^{1}$ \\ ${ }^{1}$ University of Koblenz-Landau
}

December 22, 2020

\begin{abstract}
This study investigates potential effects of wetland restoration on storm flow dynamics in a mainly waterlogged low mountain range catchment located in SW-Germany. Here, wetland drainage networks are being sealed, aiming to achieve rising soil water tables and reestablished peat vegetation. With the help of hydrograph separation, multiple linear regression (MLR) and covariance analysis (ANCOVA), runoff-governing storm properties and sealing influences were analyzed. Results show, that not only natural storm parameters (precipitation sum, rainfall intensity, antecedent precipitation and temperature) exert influence on storm-runoff, but sealings also led to significantly altered processes: On the one hand, storm-runoff coefficients increased in sealed catchments, resulting most likely from more saturated soils, providing a smaller infiltration capacity. This is a desired effect of rewetting but coincidently a downside regarding storm flood prevention. On the other hand, lag times, meaning the timespan between rainfall occurrence and the hydrograph starting to rise, were noticeably prolonged. This effect potentially can be beneficial when it comes to storm flood prevention. Overall, statistical models including sealings showed more satisfactory results describing stormflow variance compared to models without sealings. Therefore, sealings do exert - statistically proven - an effect on storm runoff. The heterogeneity of the results, representing a dense gauge network spread over an investigation area of roughly $7.5 \mathrm{~km}^{2}$ shows, that a high-resolution sampling, both spatially and temporally, is vital. That is since runoff processes in waterlogged low mountain range catchments are still poorly understood.
\end{abstract}

\section{Hosted file}

HP Zemke main text.pdf available at https://authorea.com/users/384391/articles/500011-stormrunoff-processes-in-a-mainly-waterlogged-low-mountain-range-catchment-in-the-nationalpark-hunsr\%C3\%BCck-hochwald-sw-germany-assessing-the-impact-of-wetland-restorationusing-multiple-linear-regression-analysis-and-ancova 

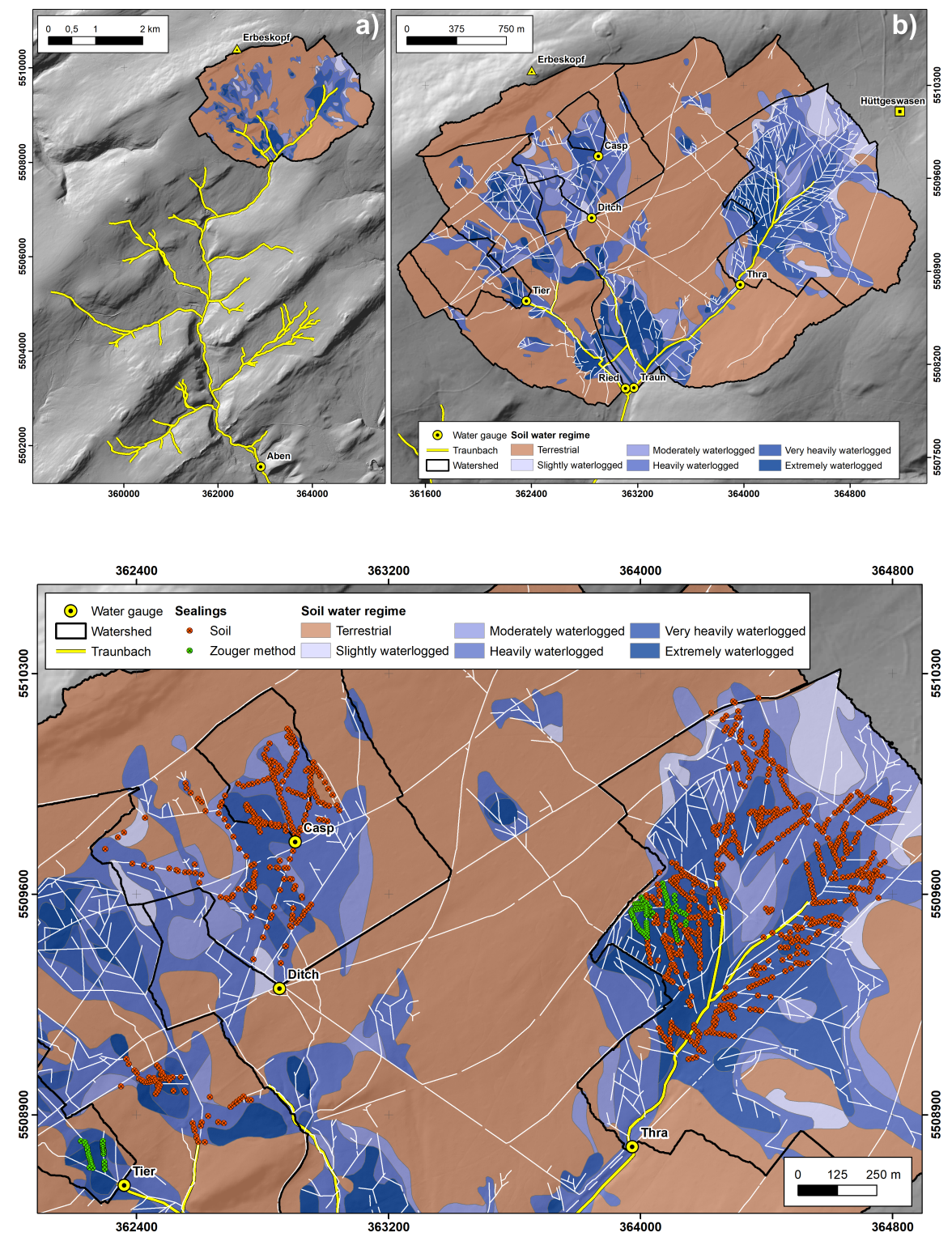

\section{Hosted file}

Figures 3 to 5.pdf available at https://authorea.com/users/384391/articles/500011-stormrunoff-processes-in-a-mainly-waterlogged-low-mountain-range-catchment-in-the-nationalpark-hunsr\%C3\%BCck-hochwald-sw-germany-assessing-the-impact-of-wetland-restorationusing-multiple-linear-regression-analysis-and-ancova 

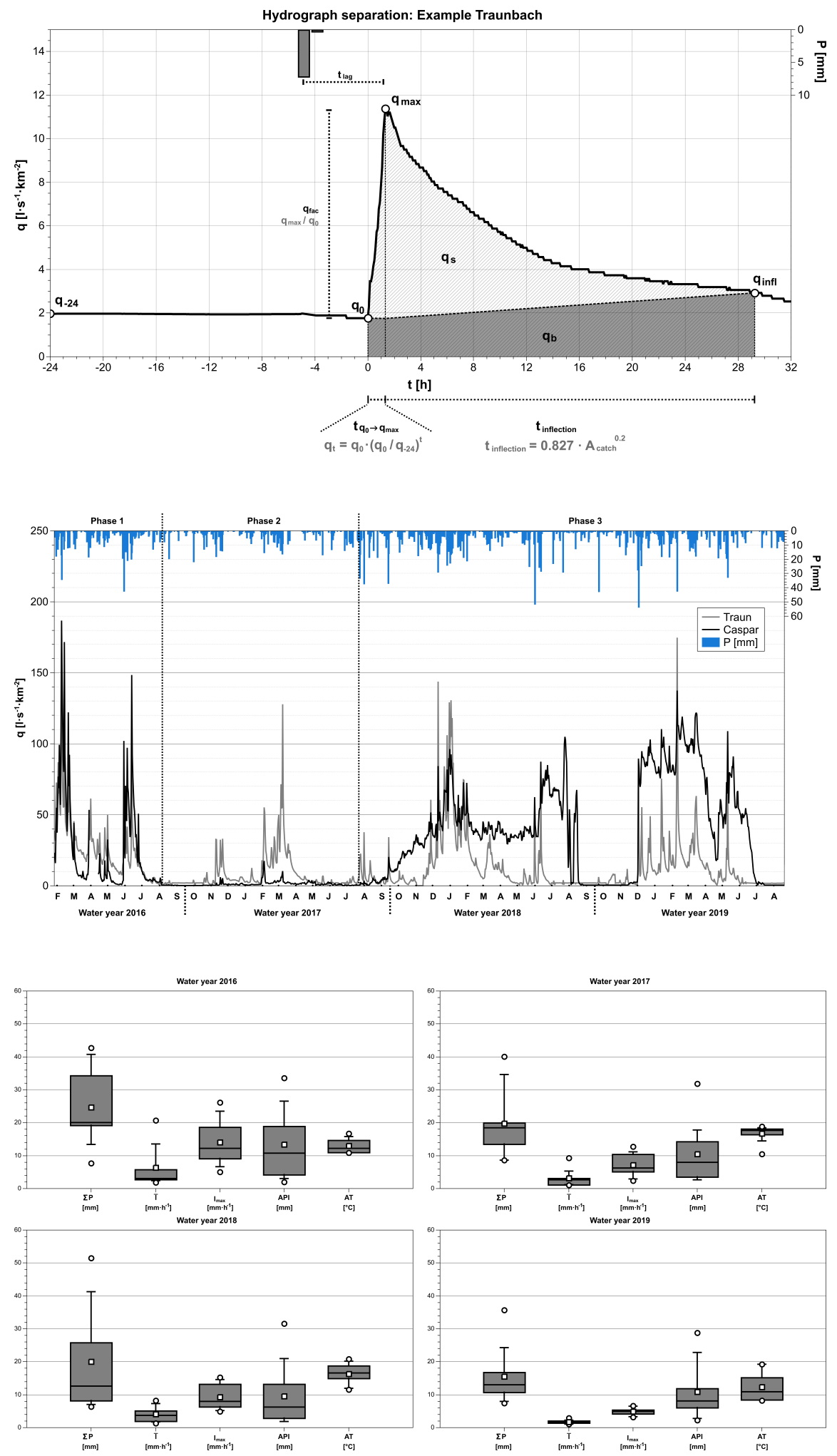

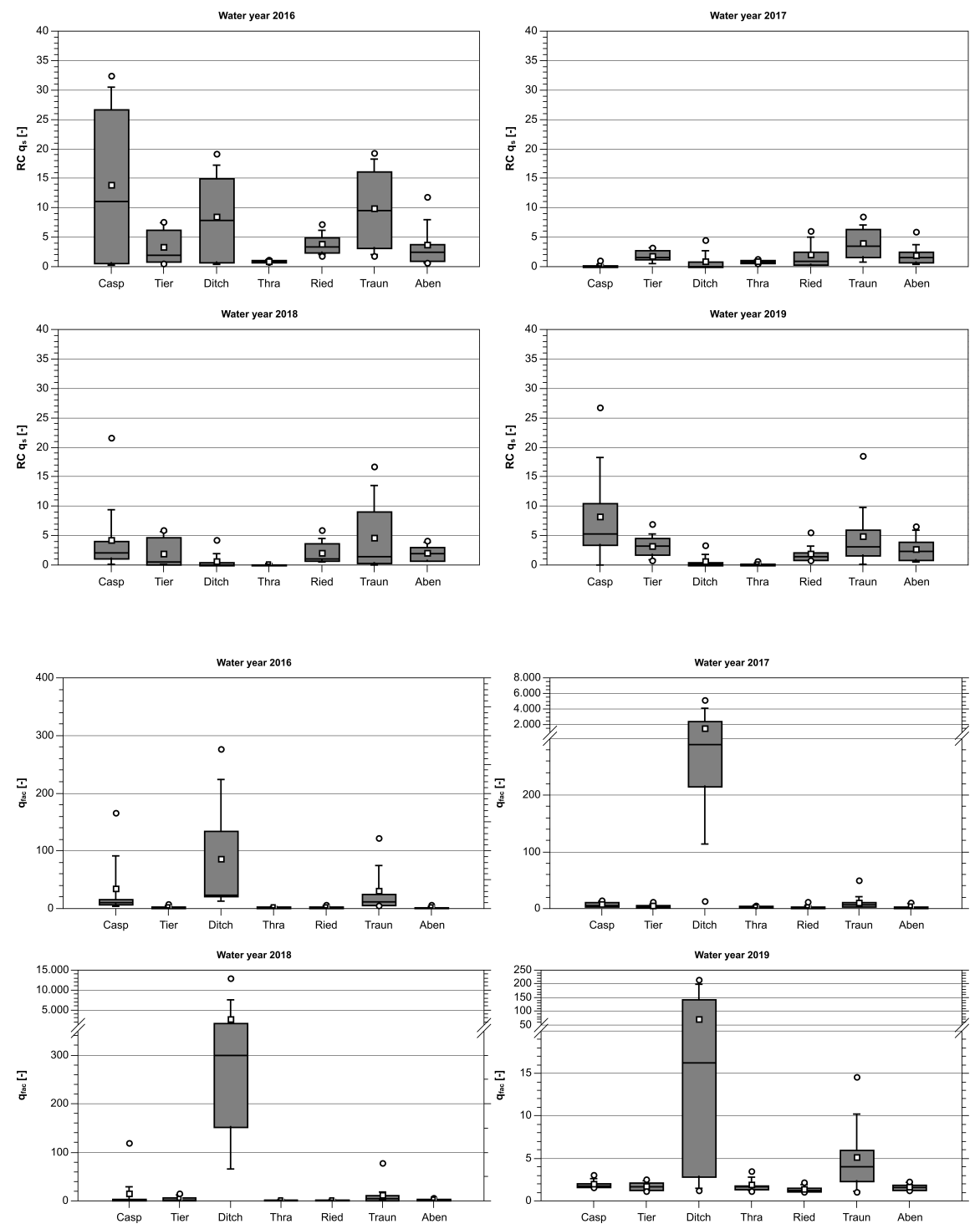

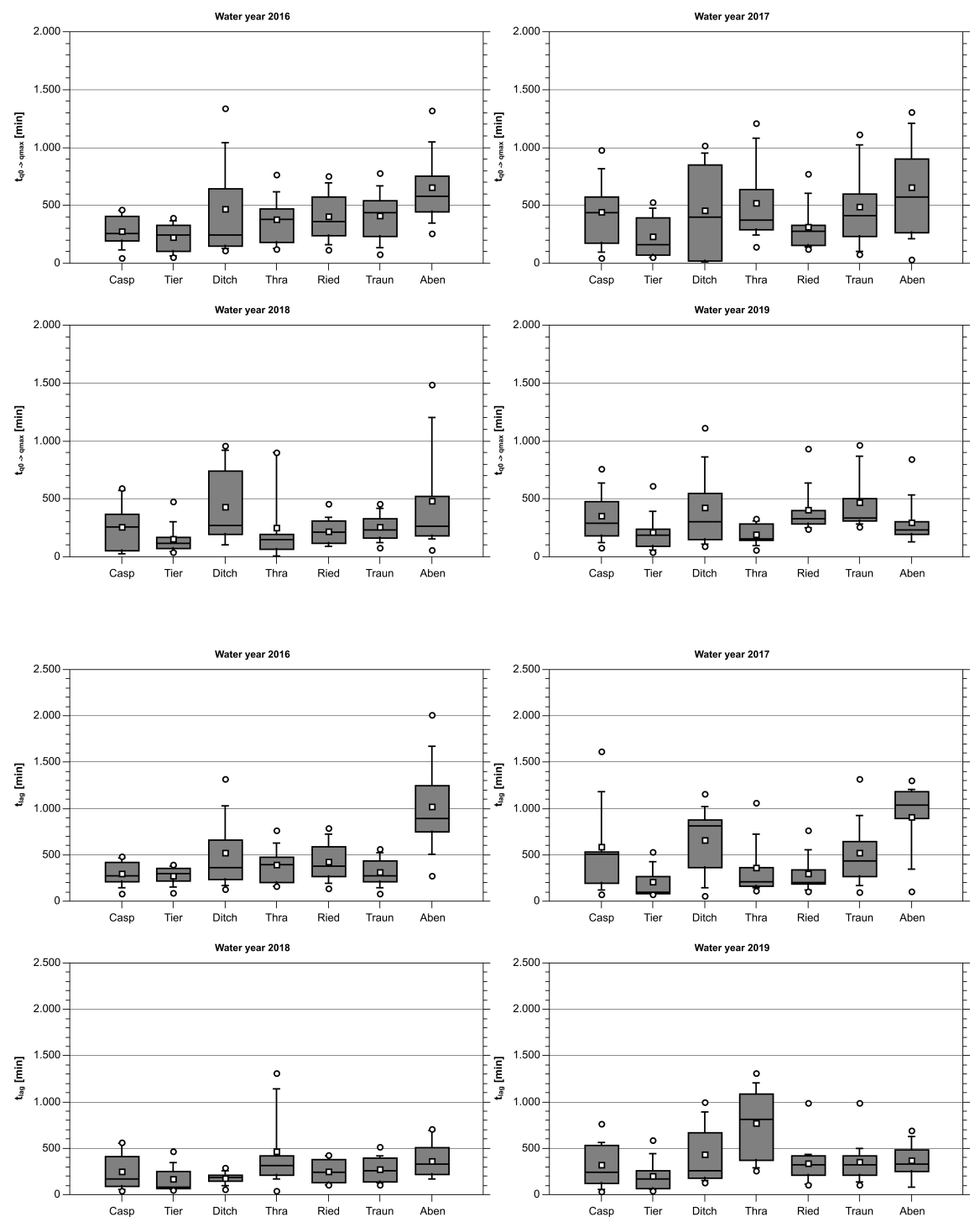